\title{
Study on the Intraspecific and Interspecific Competition of Pseudolarix amabilis in Changxing County, Zhejiang Province
}

\author{
Chun-Ping Xie ${ }^{1,2 *}$, Da-Wei Liu ${ }^{2 * *}$, Chen-Yang Huang², Jian $\mathrm{He}^{2}$ \\ ${ }^{1}$ College of Coastal Agricultural Sciences, Guangdong Ocean University, Zhanjiang 524088, China \\ ${ }^{2}$ Faculty of Criminal Science \& Technology, Nanjing Forest Police College, Nanjing 210023, China
}

Received: 6 October 2020

Accepted: 11 November 2020

\begin{abstract}
Pseudolarix amabilis (Nelson) Rehd. is a rare and endangered plant endemic to China that has played a vital role in the study of Pinaceae phylogeny. Because of the serious effects of external factors, the wild populations are gradually decreasing. To illustrate the competition in the P. amabilis community, the intra- and interspecific competition of $P$. amabilis in Changxing County, Zhejiang Province, were investigated based on the Hegyi individual competition index (CI) model. The relationships between 21 target trees and 454 competitor trees within the P. amabilis community were analysed by using the competition intensity. The results indicated that competitive stress to the $P$. amabilis population mainly came from interspecific competition, which accounted for approximately $70 \%$ of the total. The intensity of interspecific competition with P. amabilis followed the order of P. amabilis $>$ Phyllostachys edulis $>$ Castanea mollissima $>$ Quercus chenii $>$ Rhus chinensis $>$ Acer davidii $>$ Ilex chinensis $>$ Platycarya strobilacea $>$ Lindera glauca $>$ Castanopsis sclerophylla. The value of the competition index decreased with increasing distance. The CI of $P$. amabilis with the target trees in the whole forest stand was significantly negatively correlated with the DBH of the target trees and followed the power function $\left(\mathrm{CI}=A D^{-B}\right)$. In terms of the competition model, effective artificial measures should be implemented to improve the survival of $P$. amabilis, which could help restore the wild population.
\end{abstract}

Keywords: Pseudolarix amabilis, intraspecific competition, interspecific competition, competition index, Changxing county

\section{Introduction}

Competition is a common phenomenon among plant individuals in a forest, and competition is a major ecological process that plays an important role

*e-mail: xcp@gdou.edu.cn

**e-mail:dwliu@nfpc.edu.cn in the population growth rate, survival, mortality, dynamics and species replacement in forests $[1,2]$. In addition, intraspecific and interspecific competition also reflect the competence of species to absorb the limited resources in a specific stand, such as light, nutrients, and water [3-5]. The result of competition is that an organism hinders the normal growth and development of another organism [6]. Hence, competition not only causes death and self-sparing of plant individuals 
in a stand but also alters the relationship between plastic and allometric growth among competitors [7]. Simultaneously, competition is an intrinsic factor driving the succession and dynamics of a forest [8, 9]. Therefore, understanding the intraspecific and interspecific competition in a forest is critical for revealing the ecological adaptation mechanisms among individuals, forecasting stand development patterns and assessing community organization, as well as maintaining sustainable forest management [10].

The quantification of the relationship and intensity of competition among species using various indices is a popular research topic. In general, competition between tree species should be mirrored by the crown structures, sizes, basal area increments, forms, and stem girth increments of species [11-15]; furthermore, timber quality has found to demonstrate a positive relationship with the competition intensity in a stand [16]. Hence, competition indices can be divided into two categories [14]: (1) distance-independent indices that use only nonspatial information about aggregate tree size and number within a given area, for instance, Sdr [17] and BALMOD [18]; and (2) distance-dependent indices that also incorporate the relative locations of neighbouring trees within the area, such as Hegyi [19], and Sdrl2 [11]. However, those competition indices have possible shortcomings, and they can be flawed and misapplied; thus, they need to be used appropriately and with care [20]. Despite these shortcomings, Hegyi is one of the most popular indices for studying competition because of its advantages of easy operation and clear results $[6-8,14]$. Hegyi can be used to reflect the relationship between the growth and spatial patterns of individuals as a function of the diameter at breast height (DBH) and distance among trees, which also reflects the demands of species for environmental resources in real habitats [21].

Competition is a driving force for the succession and development of forests. Competition not only affects the growth of individual plants and the population structure of trees but also plays a vital role in the evolution, population and spatial patterns of a species. Thus, it has significant meaning to study the intraspecific and interspecific competition for forest plants [22-24]. In China, many studies for competition of important forest plants have been carried out in various climate zone such as Pinus yunnanensis, Castanopsis eyrie, Abies fargesii and Quercus wutaishanica [21, 25-28]. Furthermore, the competitive situation of endangered plants is an important basis for guiding conservation and recovery efforts, and endangered plants in different competitive situations required different conservation measures [29]. Hence, many rare and endangered plants were also concerned with the intra- and inter-species competition [6, 29-31]. These research results had provided an important theoretical basis for the exploitation of forest resources and the recovery of endangered plant populations [32].
Pseudolarix amabilis (Nelson) Rehd. is a deciduous tree belonging to the Pinaceae family, and it has been listed as a national key protection plant in China. Although this species is distributed within only a few areas from East China to Central China [33], its survival status is poor due to its small population size, human disturbance, climate change and other comprehensive factors [34]. According to the results of a literature review on this species [35], most studies focused on resource mining and species conservation, breeding and cultivation techniques, root mycorrhizal fungi, and the occurrence and control of golden larch olethreutid moth outbreaks; however, the research on this species is still limited. Previous field surveys indicated that the population faces a serious threat due to the lack of saplings and seedlings in the stands [34]. On the one hand, such circumstances are caused by biological characteristics; on the other hand, it is still unclear whether these threats are caused by intraspecies or interspecies competition. Consequently, the main objective of this study was to explain the intensity of intraspecies and interspecies competition for $P$. amabilis in Zhejiang Province, China. Further objectives were to reveal the living status, population dynamics and ecological adaptation mechanisms of the species to provide a scientific measure for the conservation and restoration of the $P$. amabilis population.

\section{Materials and Methods}

\section{Study Area}

The study was conducted in Changxing County of Zhejiang Province (located at approximately 30 $43^{\prime}$ $31^{\circ} 11^{\prime} \mathrm{N}, 119^{\circ} 33^{\prime}-120^{\circ} 06^{\prime} \mathrm{E}$ ), which is a transition area from low hills to the west coastal plain of Taihu Lake. The climate is subtropical marine monsoon, which is characterized by four distinct seasons: simultaneous rain and heat and plenty of rainfall. The mean annual temperature in the area is $15.6^{\circ} \mathrm{C}$, and the coldest and warmest months generally occur in January and July with temperatures ranging from $-0.4-5.5^{\circ} \mathrm{C}$ and $24.4-30.8^{\circ} \mathrm{C}$, respectively. The average annual precipitation is approximately $1300 \mathrm{~mm}$, and $75 \%$ of the rainfall is concentrated from March to September, particularly in summer. The average annual sunshine duration is approximately 1810 hours, and the percentage of sunshine throughout the year is $41 \%$. The soil in the area can be divided into four categories: loamy soil (50.84\%), paddy soil (34.52\%), chao soil $(12.89 \%)$ and lithologic soil $(1.75 \%)$. On the basis of previous investigations, the dominant species in the stand were Phyllostachys edulis, Ilex chinensis, Rhus chinensis, Castanopsis sclerophylla, Castanea mollissima, and Dalbergia hupeana. In the shrub layer, Camellia sinensis, Ph. heteroclada, Rosa multiflora, Eurya spp. were usually recorded. 


\section{Sample Design}

To conform to the experimental requirements, 21 plots were selected in the concentrated distribution area within the $P$. amabilis stand. A single stemmed $P$. amabilis was sampled in the overstory as a target tree (a total of 21 individuals). The target trees served as the centre of a circular plot (radius of $6 \mathrm{~m}$ ), in which all trees with a $\mathrm{DBH} \geq 2 \mathrm{~cm}$ were measured. Target trees were defined as the coordinate origins to establish four quadrants, and the $\mathrm{X}$ axis and $\mathrm{Y}$ axis denote north-south and east-west, respectively. In the different quadrants, the distance and coordinate angles from the target trees to the neighbours were measured from stem base to stem base, and all trees were determined to the species level. For all target trees and neighbours, the $\mathrm{DBH}$, total tree height and crown radii were measured [4, 36]. Environmental factors were also recorded, such as the location, altitude, direction, slope, soil type, canopy density, litter, and soil humus.

\section{Data Analysis}

In this study, the Hegyi index was used to calculate the intensity of intraspecific and interspecific competition [19]. The equation is: $\mathrm{CI}=\sum_{j=1}^{N}\left(\frac{D_{j}}{D_{i}} \cdot \frac{1}{D_{i j}}\right)$, where $D_{j}$ is the DBH $(\mathrm{cm})$ of the neighbouring tree, $D_{i}$ is the DBH $(\mathrm{cm})$ of the target tree, $D_{i j}$ is the horizontal distance (m) between the neighbouring and target trees, and $N$ is the count of neighbouring trees. Hence, a higher competition index (CI) value means more competition from the neighbouring trees [37]. The intraspecific CI, interspecific CI and total CI of the stand were all calculated based on the Hegyi index.

The DBH of an individual has great influence on competition in the stand. To disclose whether the DBH of $P$. amabilis affects the competitive pressure of the neighbouring trees, the power function was used to fit the regression of the target $\mathrm{DBH}$ and $\mathrm{CI}$ [31]. The formula for the regression is $\mathrm{CI}=A D^{-B}$, where $\mathrm{D}$ is the $\mathrm{DBH}$ of the target trees, and $\mathrm{A}$ and $\mathrm{B}$ are model parameters.

\section{Results}

\section{Basic Information on the Target and Neighbouring Trees}

Twenty-one target trees were conducted in the study, and the mean DBH was $26.3 \mathrm{~cm}$, ranging from 18.1-35.8 cm; the mean height was $16.4 \mathrm{~m}$, ranging from 11.0-22.0 m. Surrounding the target trees, 454 neighbouring trees were recorded, whose mean $\mathrm{DBH}$ and mean height were $10.4 \mathrm{~cm}(2.0-35.1 \mathrm{~cm})$ and $8.3 \mathrm{~m}$ (1.8-18.5 m), respectively (Table 1).

According to the distribution pattern of $\mathrm{DBH}$ in Table 1, the number of target trees decreased gradually with increasing DBH class, which was shown as a pyramid. There were no significant differences between the target trees and neighbouring trees in terms of the mean DBH of each class. The same circumstance was true for the comparison of tree height. However, the target trees were obviously higher than the neighbouring trees in the 30-35 and $>35 \mathrm{~cm}$ classes. Excluding the accidental factor of scarcity of large-scale neighbouring trees, the conclusion could be reached that the mean DBH of both target trees and neighbouring trees increased with the increase in the mean height. In the study area, approximately $81 \%$ of the target trees were classified into the $20 \mathrm{~cm}$ to $35 \mathrm{~cm}$ class; in contrast, nearly $80.0 \%$ of the neighbouring trees were included in the $0-15 \mathrm{~cm}$ class, especially in the first class with 133 individuals. Hence, a small class of neighbouring trees was likely to have more competitive pressure on $P$. amabilis in the same class.

Table 1. DBH class distribution patterns for Pseudolarix amabilis and neighbouring trees.

\begin{tabular}{|c|c|c|c|c|c|c|c|c|}
\hline \multirow{2}{*}{$\begin{array}{c}\text { DBH } \\
\text { class/cm }\end{array}$} & \multicolumn{2}{|c|}{ Individuals } & \multicolumn{2}{c|}{ Percent $\%$} & \multicolumn{2}{c|}{ Mean DBH/cm } & \multicolumn{2}{c|}{ Mean height/m } \\
\cline { 2 - 10 } & Target tree & $\begin{array}{c}\text { Neighbouring } \\
\text { tree }\end{array}$ & Target tree & $\begin{array}{c}\text { Neighbouring } \\
\text { tree }\end{array}$ & Target tree & $\begin{array}{c}\text { Neighbouring } \\
\text { tree }\end{array}$ & \multicolumn{2}{c|}{$\begin{array}{c}\text { Target tree } \\
\text { Neighbouring } \\
\text { tree }\end{array}$} \\
\hline $2-5$ & 0 & 133 & 0 & 29.30 & 0 & 3.36 & 0 & 3.78 \\
\hline $5-10$ & 0 & 107 & 0 & 23.57 & 0 & 6.81 & 0 & 6.03 \\
\hline $10-15$ & 0 & 117 & 0 & 25.77 & 0 & 12.13 & 0 & 11.28 \\
\hline $15-20$ & 3 & 36 & 14.29 & 7.93 & 18.83 & 17.36 & 13.03 & 12.20 \\
\hline $20-25$ & 5 & 37 & 23.81 & 8.15 & 23.24 & 22.29 & 15.92 & 13.43 \\
\hline $25-30$ & 8 & 19 & 38.10 & 4.19 & 27.21 & 27.43 & 16.98 & 14.88 \\
\hline $30-35$ & 4 & 4 & 19.05 & 0.88 & 31.40 & 31.70 & 17.75 & 13.28 \\
\hline$>35$ & 1 & 1 & 4.76 & 0.22 & 35.80 & 35.10 & 18.00 & 15.00 \\
\hline Total & 21 & 454 & 100 & 100 & - & - & - & - \\
\hline
\end{tabular}


Table 2. Intraspecific and interspecific competition intensity of Pseudolarix amabilis in each DBH class.

\begin{tabular}{|c|c|c|c|c|c|c|c|}
\hline \multirow{2}{*}{ DBH class/cm } & \multicolumn{3}{|c|}{ Intraspecific competition } & \multicolumn{3}{|c|}{ Interspecific competition } & \multirow{2}{*}{ Total Cl } \\
\hline & Individuals & $\mathrm{CI}$ & Mean CI & Individuals & $\mathrm{CI}$ & Mean CI & \\
\hline $2-5$ & 0 & 0 & 0 & 133 & 7.55 & 0.06 & 7.55 \\
\hline $5-10$ & 1 & 0.05 & 0.05 & 106 & 11.88 & 0.11 & 11.93 \\
\hline $10-15$ & 4 & 1.62 & 0.41 & 113 & 18.58 & 0.16 & 20.20 \\
\hline $15-20$ & 14 & 5.49 & 0.39 & 22 & 3.89 & 0.18 & 9.38 \\
\hline $20-25$ & 26 & 7.76 & 0.30 & 11 & 2.29 & 0.21 & 10.05 \\
\hline $25-30$ & 15 & 3.43 & 0.23 & 4 & 2.62 & 0.65 & 6.05 \\
\hline $30-35$ & 2 & 2.32 & 1.16 & 2 & 0.42 & 0.21 & 2.74 \\
\hline$>35$ & 0 & 0 & 0 & 1 & 0.20 & 0.20 & 0.20 \\
\hline Total & 62 & 20.68 & - & 392 & 47.43 & - & 68.11 \\
\hline
\end{tabular}

Intra- and Interspecific Competition of $P$. amabilis

Target trees exhibited intraspecific and interspecific competitive relationships during the process of growth and development, and the competition intensity was closely related to the individual number and size of the trees. Based on the intraspecific and interspecific competition intensity of $P$. amabilis in each $\mathrm{DBH}$ class (Table 2), the total CI was 68.11 , including 20.68 $(30.36 \%$ of the total CI) for intraspecific CI and 47.43 (69.64\% of total CI) for interspecific CI. The result indicated that the pressure of $P$. amabilis mainly came from interspecific competition, which would influence

Table 3. Competition intensity of neighbouring trees.

\begin{tabular}{|c|c|c|c|c|c|c|c|}
\hline Tree species & Individuals & Percent $/ \%$ & Mean DBH/cm & Mean height $/ \mathrm{m}$ & $\mathrm{CI}$ & Mean CI & Rank \\
\hline Pseudolarix amabilis & 62 & 13.66 & 21.98 & 14.76 & 20.68 & 0.33 & 1 \\
\hline Phyllostachys edulis & 95 & 20.93 & 11.78 & 12.40 & 17.83 & 0.19 & 2 \\
\hline Castanea mollissima & 17 & 3.74 & 18.82 & 7.25 & 3.22 & 0.19 & 3 \\
\hline Quercus chenii & 6 & 1.32 & 17.23 & 12.42 & 2.53 & 0.42 & 4 \\
\hline Rhus chinensis & 31 & 6.83 & 5.27 & 4.90 & 2.04 & 0.07 & 5 \\
\hline Acer davidii & 8 & 1.76 & 4.80 & 4.99 & 1.87 & 0.23 & 6 \\
\hline Dalbergia hupeana & 12 & 2.64 & 12.30 & 8.24 & 1.76 & 0.15 & 7 \\
\hline Ilex chinensis & 22 & 4.85 & 7.43 & 6.64 & 1.71 & 0.08 & 8 \\
\hline Platycarya strobilacea & 16 & 3.52 & 8.64 & 6.59 & 1.70 & 0.11 & 9 \\
\hline Lindera glauca & 21 & 4.63 & 4.48 & 4.55 & 1.57 & 0.07 & 10 \\
\hline Castanopsis sclerophylla & 25 & 5.51 & 6.50 & 4.88 & 1.40 & 0.06 & 11 \\
\hline Ligustrum quihoui & 5 & 1.10 & 5.22 & 2.54 & 0.88 & 0.18 & 12 \\
\hline Celtis sinensis & 7 & 1.54 & 10.63 & 6.40 & 0.75 & 0.11 & 13 \\
\hline Euonymus maackii & 15 & 3.30 & 4.15 & 4.11 & 0.74 & 0.05 & 14 \\
\hline Lonicera maackii & 1 & 0.22 & 4.80 & 4.70 & 0.70 & 0.70 & 15 \\
\hline Liquidambar formosana & 5 & 1.10 & 12.47 & 10.40 & 0.64 & 0.13 & 16 \\
\hline Euonymus alatus & 2 & 0.44 & 7.85 & 5.50 & 0.57 & 0.29 & 17 \\
\hline Acer ginnala & 6 & 1.32 & 5.00 & 4.08 & 0.55 & 0.09 & 18 \\
\hline Ilex cornuta & 11 & 2.42 & 4.54 & 3.38 & 0.52 & 0.05 & 19 \\
\hline Other species & 87 & 19.14 & 7.58 & 5.52 & 6.46 & 0.07 & - \\
\hline
\end{tabular}


the pattern and dynamics of the $P$. amabilis population. Under intraspecific competition, the value of CI was 16.68 (80.7\% of the total intraspecific CI) in the $15-30 \mathrm{~cm}$ class, which means that intraspecific competition was concentrated among adults. Furthermore, the CI value was 38.01 (80.1\% of the total interspecific CI) in the $2-15 \mathrm{~cm}$ class under interspecific competition. The highest value of intraspecific CI was 7.76 in the $20-25 \mathrm{~cm}$ class, which was the middle class. This result probably occurred because there were few individuals in the small and large classes. The competition intensity between $P$. amabilis and neighbouring trees increased with increasing DBH class, and the maximum CI was 18.58 in the $10-15 \mathrm{~cm}$ class. However, after that, the competition intensity began to decrease with increasing DBH class due to the scarcity of neighbouring trees. In addition, the maximum $\mathrm{CI}$ of interspecific competition (18.58) was two times greater than that of intraspecific (7.76).

According to the competition intensity of each neighbouring tree species throughout the stand (Table 3), P. amabilis had the highest CI value (20.68, $30.36 \%$ of the total CI in the whole stand). Phyllostachys edulis followed with a value of $17.83(26.17 \%)$ because of numerous individuals. The remaining tree species had CI values from 0.02 to 3.22 , with approximately 280 individuals. For $P$. amabilis, the rank of intraspecific and interspecific competition intensity throughout the stand was as follows: P. amabilis $>P h$. Edulis $>$ Castanea mollissima $>$ Quercus chenii $>$ Rhus chinensis $>$ Acer davidii $>$ Dalbergia hupeana $>$ Ilex chinensis $>$ Platycarya strobilacea $>$ Lindera glauca $>$ Castanopsis sclerophylla.

\section{Relationship between CI and the Distance from the Target Tree to Neighbouring Trees}

The relationship between $\mathrm{CI}$ and the distance from the target tree to the neighbouring tree followed the power function (Fig. 1), and the fitting function was $y=0.249 x^{-0.81}\left(R^{2}=0.304, p<0.01\right)$. The CI value

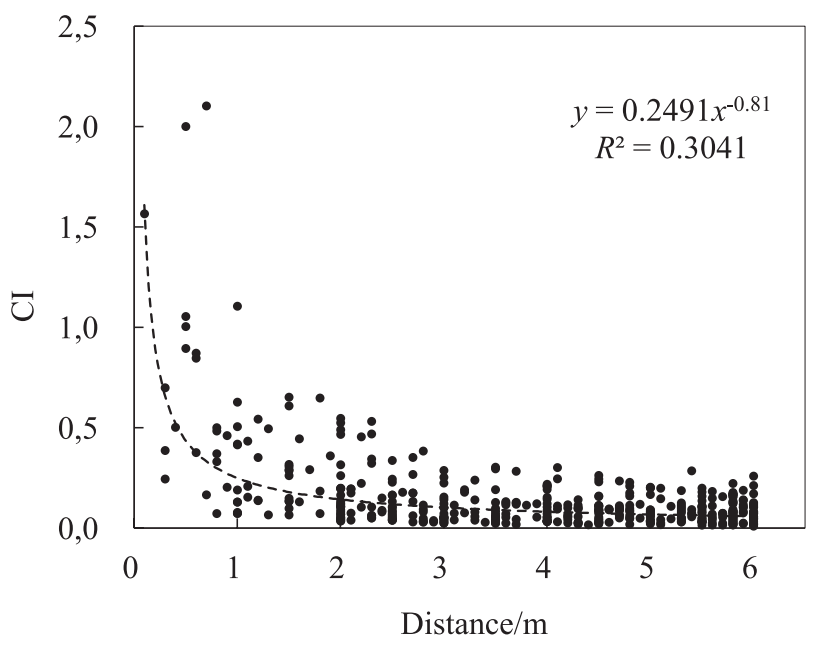

Fig. 1 Relationship between distance and CI. increased suddenly when the distance was less than $1 \mathrm{~m}$, reaching a value of 2.10 . However, the CI value decreased obviously when the distance between the target tree and neighbouring tree was greater than $1 \mathrm{~m}$, as most of the CI values were less than 0.5. Finally, the fitting curve is shown as a straight line at a low level.

\section{Predicting the Relationship between the DBH of the Target Tree and CI}

The competitive competence of a tree species is limited by different factors, such as individual size, habitat, and environmental resources. However, the most important factor affecting the competitive competence of neighbouring trees was the $\mathrm{DBH}$ of the target tree [38]. The DBH of the target trees and CI were fitted via a regression, and the fitting curves in Fig. 2 are for $P$. amabilis and the whole stand, intraspecific competition of $P$. amabilis, $P$. amabilis and neighbouring trees, and $P$. amabilis and $P h$. edulis, with the fitted functions of $\mathrm{CI}_{\text {stand }}=3.351 x^{-1.1}, \mathrm{CI}_{\text {intraspecific }}=3.299 x^{-0.799}$, $\mathrm{CI}$ interspecific $=0.631 x^{-0.633}$ and CI ${ }_{\text {Ph. edulis }}=1.639 x^{-0.747}$, respectively. According to the test, there was a significant relationship between the $\mathrm{DBH}$ of target trees and the $\mathrm{CI}$ of the whole stand $\left(\mathrm{R}^{2}=0.043, p<0.01\right)$ as well as the DBH of the target trees and the CI of neighbouring trees $\left(\mathrm{R}^{2}=0.016, p<0.05\right)$. Nevertheless, there was no significant correlation between the $\mathrm{DBH}$ of target trees and the CI of Ph. edulis $\left(\mathrm{R}^{2}=0.042, p>0.1\right)$, which was the same as the intraspecific competition of P. amabilis $\left(\mathrm{R}^{2}=0.018, p>0.1\right)$. In addition, the CI was generally low (Fig. 2), which means that the larger the $\mathrm{DBH}$ of the target trees was, the weaker the competition from neighbouring trees. The competition intensities of the four types of $P$. amabilis decreased with the increasing DBH of the target trees, which is clearly demonstrated in Fig. 2.

Intraspecific and interspecific competition of $P$. amabilis was simulated and predicted for the different DBH classes in the model (Table 4). The results indicated that the CI decreased with the increase in the $\mathrm{DBH}$ of the target trees. There was a turning point at a DBH of $15 \mathrm{~cm}$. When the DBH of $P$. amabilis was less than $15 \mathrm{~cm}$, the species exerted greater competitive pressure on the target trees, and the opposite occurred when the DBH was greater than $15 \mathrm{~cm}$.

\section{Discussion}

In this study, the Hegyi index was used to illustrate the intensity of intraspecific and interspecific competition in a $P$. amabilis stand. Based on the results from 21 target trees and 454 neighbouring trees, the Hegyi index for intraspecific competition was 20.68, but it was much smaller than that for interspecific competition, which was 47.43. Therefore, the competition pressure of $P$. amabilis came mainly from interspecific competition. At the same time, these 


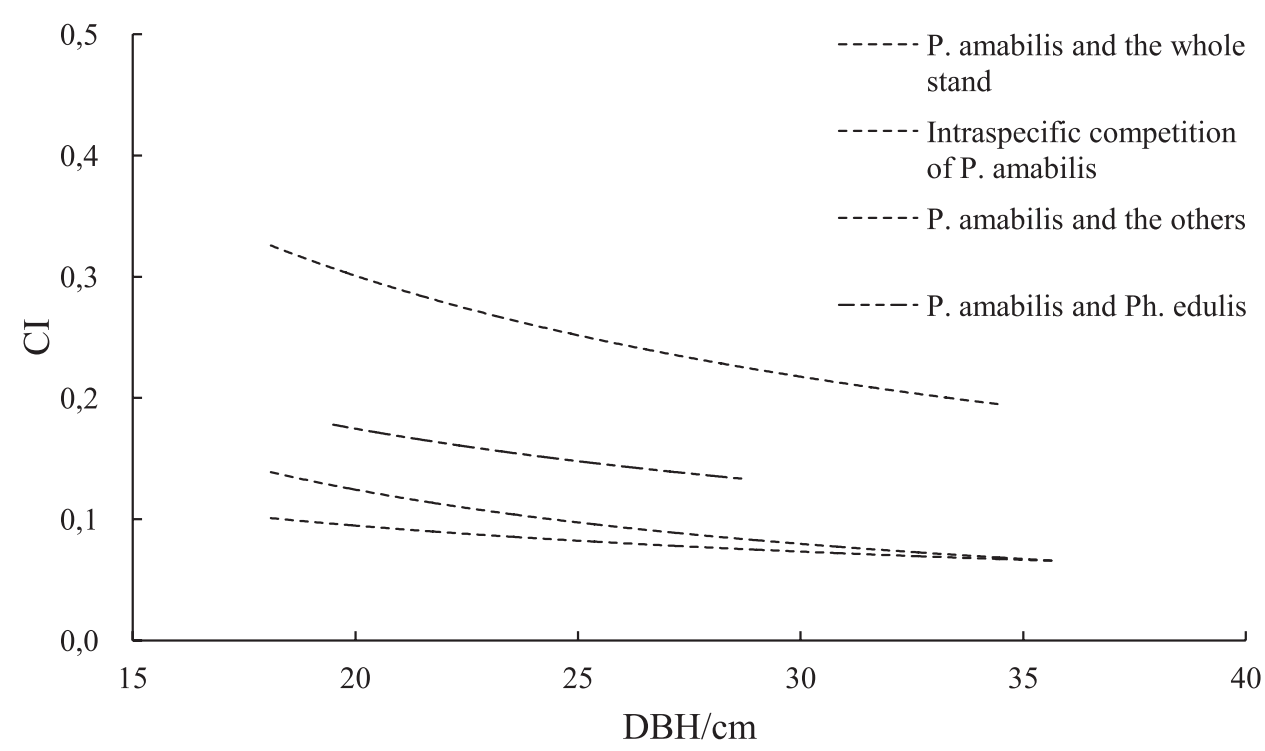

Fig. 2 Regression curves of competition intensity and DBH of Pseudolarix amabilis.

Table 4. Model predictions of intraspecific and interspecific competition intensity and DBH.

\begin{tabular}{|c|c|c|c|c|c|c|c|c|}
\hline \multirow{2}{*}{ Sort } & \multicolumn{7}{|c|}{$\mathrm{DBH} / \mathrm{cm}$} \\
\cline { 2 - 10 } & $2-5$ & $5-10$ & $10-15$ & $15-20$ & $20-25$ & $25-30$ & $30-35$ & $35-40$ \\
\hline P. amabilis and the whole stand & 0.10 & 0.03 & 0.02 & 0.01 & 0.01 & 0.01 & 0.01 & 0.01 \\
\hline P. amabilis and the others & 0.75 & 0.37 & 0.27 & 0.22 & 0.19 & 0.16 & 0.15 & 0.13 \\
\hline Intraspecific competition of P. amabilis & 0.19 & 0.08 & 0.05 & 0.04 & 0.03 & 0.03 & 0.02 & 0.02 \\
\hline P. amabilis and Ph. edulis & 0.35 & 0.15 & 0.10 & 0.08 & 0.07 & 0.06 & 0.05 & 0.05 \\
\hline
\end{tabular}

results also reflected the scattered distribution pattern of $P$. amabilis throughout the stand. This phenomenon was similar to patterns found for other endangered species, such as Pinus dabeshanesis [37], Magnolia zenii [6], and Parrotia subaequalis [39] in natural forests. These trees all had the characteristics of sparse individuals, scattered distribution, and strict requirements for living environments [31, 35, 37].

(1) The relationship between the competition intensity and the DBH of target trees. The relationship between the competition intensity and DBH of target trees could be displayed by a power function, which was: $C I=A D^{-\mathrm{B}}$. This result was consistent with the results of previous studies, for example Taxus yunnanensis [21], Pinus dabeshanesis [37], Machilus thunbergia [38], and Pinus tabuliformis [40]. The regression curve equations (Fig. 1) and model predictions indicate that the larger the $\mathrm{DBH}$ of the target trees is, the less competitive pressure they received. When the $\mathrm{DBH}$ of $P$. amabilis was less than $15 \mathrm{~cm}$, the competitive pressure on them was greatest; however, when the DBH was larger than $15 \mathrm{~cm}$, the competitive pressure was gradually reduced and remained at a low level. When $P$. amabilis remain in the understory as saplings or seedlings, they require more resources and space, such as light, water, heat, and soil. However, their competitiveness is weak, and more competition comes from the neighbouring trees. With the increase in the DBH of P. amabilis, they are able to obtain more resources from the environment, which also helps them enhance their competitiveness in the stand. A similar situation was found in a population of Ulmus lamellose [41]. Therefore, to improve the regeneration capacity of the $P$. amabilis population, specific measures should be adopted to increase the individuals in the population in the forest layer for regeneration, such as by employing selective cutting and artificial tending measures. Particularly, appropriate artificial interference could be deployed in the community when $P$. amabilis is at lower age levels $(\mathrm{DBH}<15 \mathrm{~cm})$, which will be beneficial for the regeneration of $P$. amabilis (Fig. 2).

(2) The Hegyi index was influenced by the distance from target trees to neighbouring trees. The competition among individuals varies not only with different tree species and DBH but also with the distance between neighbouring and target trees. The relationship between the Hegyi index and the distance from target trees to neighbouring trees obeyed the power function. This finding indicated that the Hegyi index gradually decreased as the distance between target and neighbouring trees increased and finally approached zero. When the distance between the target and 
neighbouring trees was less than $1 \mathrm{~m}$, the Hegyi index reached 2.10; however, when the distance between trees was greater than $1 \mathrm{~m}$, the Hegyi index was generally low, which was the case for most trees. Therefore, most of the Hegyi index values were below 0.5 (Fig. 1). In this study, we discussed the effects of only DBH and distance on the competition intensity, but other factors also need to be further explored.

(3) Impact of community succession stage on species competition. The interspecific competition intensity of $P$. amabilis varied greatly with the different neighbouring trees; meanwhile, the more ecologically similar species exerted the stronger competition [42]; thus, the less competitive individuals in the community should eventually be replaced by the more competitive species [37]. However, the competition intensity also exhibited a certain relationship with the succession stage and changes in the community. In this study, the communities where $P$. amabilis is located should be divided into coniferous broad-leaved deciduous forests, but some species, such as Phyllostachys pubescens, Castanopsis sclerophylla, and Cyclobalanopsis glauca, had a certain number of individuals in the tree layer and shrub layer. This phenomenon indicated that the community had begun to develop into a mixed forest of deciduous and evergreen broad-leaved trees. It was not difficult to understand that the community was already in the early stage of succession, and there was fierce competition in all layers of the community. $P$. amabilis, as an earlier tree species in the community, had a greater advantage than the other species in the arbour layer, so the growth of adult trees of this species tended to be stable. However, with the development of the community and the density of the canopy, the competitiveness of $P$. amabilis seedlings was weaker than that of the other broad-leaved trees, which resulted in the absence of $P$. amabilis individuals in the shrub layer. This finding was consistent with the results of the field survey. There were many tree species competing with $P$. amabilis in the community, mainly $P h$. pubescens, Castanea mollissima, Quercus chenii, Rhus chinensis, and Acer davidii. Due to the large number of individuals (accounting for $20.93 \%$ of the total number of individuals in the whole stand), $P h$. pubescens occupied a large advantage in the community, and the greatest interspecific competition with $P$. amabilis came from $P h$. pubescens.

There was a potential threat for $P$. amabilis because of the scarcity of seedlings in the regeneration layer. On the one hand, $P$. amabilis is a high-light tree species, which requires high levels of photosynthesis in the seedling to adult stages. In addition to the light requirements, the number of individuals also decreased due to both plant interactions and self-thinning. Second, the seed dispersal of $P$. amabilis depends on wind and animals. Thus, some of the seeds are consumed by rodents such as squirrels, and some are not germinated as a result of insufficient conditions. Therefore, there were not enough seeds to sustain the population of
P. amabilis. Furthermore, as a mycorrhizal tree species, the growth of $P$. amabilis is influenced by fungi [43]. In a field survey, only one seedling was found in the community, and there were many dead trees and stumps of $P$. amabilis. This result illustrated that the population of $P$. amabilis was seriously affected by the external environment. At the same time, we interviewed the surrounding villagers and found that most did not realize the importance of $P$. amabilis and its conservation priority. Moreover, they even cleaned away $P$. amabilis seedlings to prevent interference with farming. Finally, these conditions resulted in the absence of young individuals and the unreasonable age structure of $P$. amabilis.

Therefore, it was clear that with the succession of the $P$. amabilis community, several factors should inhibit the development of $P$. amabilis, including human disturbance, the lack of seedlings, and germination difficulty. Finally, $P$. amabilis should eventually be replaced by the other neighbouring trees mentioned above in the community.

(4) Conservation strategies and recommendations. It is urgent to protect the wild population of $P$. amabilis, and we recommend several measures. $a$. Increase publicity and education. On the one hand, through the laws and popular science publications, villagers should be made aware of the importance of $P$. amabilis conservation and the serious consequences of damaging the state's key protected plants. On the other hand, relevant government departments should set special funding for education and publications. All types of social media (such as Wechat, Microblog, Twitter, QQ) could be utilized to reach specific people in rural villages, small towns, and metropolitan areas. According to the publications, common people could be made aware of the conservation goals and the rules, which will ultimately achieve the purpose of $P$. amabilis protection. $b$. Effective scientific measures should be taken, such as in situ protection, ex situ protection and breeding centres. First, small nature reserves can be established in the concentrated areas of P. amabilis; meanwhile, ecological compensation agreements can be signed by the villagers whose lives are affected in the small nature reserves. However, villagers could also be invited to take part in the protection process, which will avoid conflicts between conservation actions and villagers' daily lives. Second, if the P. amabilis individuals cannot remain at the natural sites, they should be moved to artificial places, such as parks, botanical gardens, and arboretums. c. Artificial cultivation could be promoted using biotechnology. $P$. amabilis is one of the top five garden ornamental trees in the world, but it is difficult to find these trees in urban gardens in China. The fundamental reason is that the species has insufficient artificially cultivated individuals and low cultivation in nurseries. Therefore, we should establish a high-quality germplasm resource bank and increase artificial cultivation. Finally, the use of $P$. amabilis in garden planning and design should be promoted. 
In many studies on intraspecies and interspecies competition among forest trees, the number of target trees was selected from hundreds of individuals, such as Larix gmelina [9], Machilus thunbergia [38], and Pinus yunnanensis [25]. The target trees of these researches were mainly dominant tree species in the forest, and the number of individuals was abundant. However, rare and endangered plants, such as Magnolia zenii [6], Taxus cuspidate [31], and Cycas micholitzii [30] had fewer target trees selected. Due to the small number of individuals and strict field experiments, only 21 target trees were selected for the study. However, the research results still revealed the current status of the $P$. amabilis population and the intraspecific and interspecific competition in the populations, which provides a scientific reference for the conservation of this species.

\section{Conclusion}

The results of this study indicated that the competition for $P$. amabilis mainly came from interspecies competition within the stand. The intensity of competition was negatively correlated with the $\mathrm{DBH}$ of the target trees and the distance from the target trees to the neighbouring trees. Because of human disturbance and the incomplete structure of the population, effective measures should be taken to protect the current $P$. amabilis population in the study area.

\section{Acknowledgements}

This study was supported by the project of field rescue and breeding of rare and endangered species of the State Forestry and Grassland Administration (2019); LI Hao and Zhang Jian provided great support in the field investigation.

\section{Conflict of Interest}

The authors declare no conflict of interest.

\section{References}

1. MALEKI K., KIVISTE A., KORJUS H. Analysis of individual tree competition on diameter growth of silver birch in Estonia. Forest Systems. 24 (2), 8, 2015.

2. FRAVER S., D'AMATO A.W., BRADFORD J.B., JONSSON B.G., JöNSSON M., ESSEEN P.A. Tree growth and competition in an old-growth Picea abies forest of boreal S weden: influence of tree spatial patterning. Journal of Vegetation Science. 25 (2), 374, 2014.

3. PEET R. K., CHRISTENSEN N. L. Competition and tree death. Bioscience. 37 (8), 586, 1987.

4. VAJARI K. A. Influence of interspecies competition on beech (Fagus orientalis Lipsky) trees and some features of stand in mixed broad-leaved forest. Environ Monit Assess. 190 (7), 377, 2018.

5. CHAO L., HONG T., LI J., CHEN C., HONG W., WU C.Z. Intraspecific competition in a Cunninghamia lanceolata plantation with different age and diameter classes. Journal of Zhejiang A\&F University. 32 (3), 353, 2015.

6. JIANG G.M., SUN G., ZHANG G.F., WANG J.W. Intra-and interspecific competition of endangered plant Magnolia zenii. Chinese Journal of Ecology. 29 (2), 201, 2010.

7. LIU F.L., ZENG S.Q., XIAO H.S., LV Y., LIU Y., PENG Q.L. Competitive Growth Law of Schima superba Secondary Forest. Journal of Northwest Forestry University. 29 (1), 144, 2014.

8. AMIRI M., NAGHDI R. Assessment of competition indices of an unlogged oriental beech mixed stand in Hyrcanian forests, Northern Iran. Biodiversitas Journal of Biological Diversity. 17 (1), 306, 2016.

9. LIU Y.Q., TIAN Y.H., SONG H.Z., HUANG W.L. DBH and stand density regulate intraspecific competition of Larix gmelinii in eastern Inner Mongolia. Chinese Journal of Ecology. 37 (3), 847, 2018.

10. LV Y., QIAN S.P., LV F.Z., ZHU G.Y. Study on comprehensive competition stress index of Cyclobalanopsis glauca secondary forest. Journal of Central South University of Forestry \& Technology. 37 (10), 1, 2017.

11. MARTIN G.L., EK A.R. A comparison of competition measures and growth models for predicting plantation red pine diameter and height growth. For Sci. 30 (3), 731, 1984.

12. ANTIN C., PéLISSIER R., VINCENT G., COUTERON P. Crown allometries are less responsive than stem allometry to tree size and habitat variations in an Indian monsoon forest. Trees. 27 (5), 1485, 2013.

13. METZ J., SEIDEL D., SCHALL P., SCHEFFER D., SCHULZE E.-D., AMMER C. Crown modeling by terrestrial laser scanning as an approach to assess the effect of aboveground intra-and interspecific competition on tree growth. For Ecol Manage. 310 275, 2013.

14. CONTRERAS M.A., AFFLECK D., CHUNG W. Evaluating tree competition indices as predictors of basal area increment in western Montana forests. For Ecol Manage. 262 (11), 1939, 2011.

15. OLIVIER M.D., ROBERT S., FOURNIER R.A. Response of sugar maple (Acer saccharum, Marsh.) tree crown structure to competition in pure versus mixed stands. For Ecol Manage. 374, 20, 2016.

16. HöWLER K., ANNIGHöFER P., AMMER C., SEIDEL D. Competition improves quality-related external stem characteristics of Fagus sylvatica. Canadian Journal of Forest Research. 47 (12), 1603, 2017.

17. LORIMER C.G. Tests of age-independent competition indices for individual trees in natural hardwood stands. For Ecol Manage. 6 (4), 343, 1983.

18. SCHRöDER J., GADOW K.V. Testing a new competition index for Maritime pine in northwestern Spain. Canadian Journal of Forest Research. 29 (2), 280, 1999.

19. HEGYI F. A simulation model for managing jack-pine stands simulation. In: Fries J., ed. Growth models for tree and standsimulation. Stockholm: Royal College of Forestry Research Notes; 74, 1974.

20. WEIGELT A., JOLLIFFE P. Indices of plant competition. J Ecol. 91, 707, 2003.

21. LI S. F., LIU W. D., SU J. R., LANG X. D., ZHANG Z. J. Intra-and interspecific competitions of Taxus yunnanensis population in Jinsha River Basin of northwest Yunnan 
Province, Southwest China. Chinese Journal of Ecology. 32 (1), 33, 2013.

22. ADLER P.B., SMULL D., BEARD K.H., CHOI R.T., FURNISS T., KULMATISKI A., MEINERS J.M., TREDENNICK A.T., VEBLEN K.E. Competition and coexistence in plant communities: intraspecific competition is stronger than interspecific competition. Ecol Lett. 21 (9), 1319, 2018.

23. SAHA S., KUEHNE C., BAUHUS J. Intra- and interspecific competition differently influence growth and stem quality of young oaks (Quercus robur L. and Quercus petraea (Mattuschka) Liebl.). Annals of Forest Science. 71, 381, 2014.

24. SEIFERT T., SEIFERT S., SEYDACK A., DURRHEIM G., GADOW K.V. Competition effects in an afrotemperate forest. Forest Ecosystems. 1 (1), 119, 2014.

25. HUANG X.B., LIU W.D., SU J.R., LI S.F., LANG X.D. Intraspecific and interspecific competition of Pinus yunnanensis natural forest. For Res. 29 (2), 209, 2016.

26. JIN Z.X., ZHU X.Y., LIN H.Q. Intraspecific and interspecific competition in Castanopsis eyrei in Tiantai Mountain of Zhejiang Province. Chinese Jounal of Ecology. 23 (2), 22, 2004.

27. DUAN R.Y., WANG X.A., HUANG M.Y., TU Y.B., WANG C. Study on Intraspecific and Interspecific Competition in Abies fargesii on Taibai Mountain. Journal of Wuhan Botanical Research. 25 (6), 581, 2007.

28. FANG J., WANG X.A., GUO H., ZHU Z.H. Intraspecific and interspecific competition of Quercus liaotungensis in Malan forest region of Loess Plateau. Acta Bot BorealiOccidential Sinica. 27 (2), 334, 2007.

29. LIU S.S., MAO R., SHI F.X., WAN S.Z., WU P.P., XU J.W., ZHANG C.H. Difference in intra- and inter-specific competition of two endangered plant species (Toona ciliate var. pubescens and Taxus chinensis var. mairei) in the middle subtropical zone of China. Chinese Journal of Applied Ecology. 31 (1), 1, 2020.

30. LIN J.Y., LI J., LIANG R.L. Intraspecific and interspecific competition of Cycas micholitzii in the shrub layer. Journal of Forest and Environment. 39 (2), 159, 2019.

31. LIU T., LI Y.L., ZHOU Z.Q., HU H.Q. Intraspecific and interspecific competition of Japanese yew (Taxus cuspidata). Acta Ecologica Sinica. 27 (3), 924, 2007.

32. XU H., LIU Y.H. Relationship between Diameter Class Structure and Intraspecific and Interspecific Competitions of Precious and Endangering Plant Acer catalpifolium. Acta Bot Boreali-Occidential Sinica. 38 (6), 1160, 2018.

33. WANG L.H., YANG J.X., XU X.N. Analysis of suitable bioclimatic characteristics of Pseudolarix amabilis by using MaxEnt model. Sci Silvae Sin. 51 (1), 127, 2015.

34. XIE C.P., NAN C.H., YI X.G., WU X.K., LIU D.W. Study on community characteristics of Pseudolarix amabilis in Anji County of Zhejiang Province. Journal of Plant Resources and Environment. 27 (1), 91, 2018.

35. WU A.Q., OUYANG X.F., CHEN F.S. A review of study on the biology of Pseudolarix kaempferi in China based on the mapping knowledge domain. Nanfang Forestry Science. 45 (6), 42, 2017.

36. VON OHEIMB G., LANG A C., BRUELHEIDE H., FORRESTER D.I., WÄSCHE I., YU M., HäRDTLE W. Individual-tree radial growth in a subtropical broad-leaved forest: the role of local neighbourhood competition. For Ecol Manage. 261 (3), 499, 2011.

37. XIANG X.Y., WU G.L., DUAN R.Y., YAN Y.M., ZHANG X.P. Intraspecific and interspecific competition of Pinus dabeshanesis. Acta Ecologica Sinica. 35 (2), 389, 2015.

38. GAO H.J., GAO P.S., WANG G.M. Intraspecific and interspecific competition of Machilus thunbergii forest in Zhoushan Islands. Bulletin of Botanical Research. 37 (3), 440, 2017.

39. ZHANG G.F., YAO R., JIANG Y.Q., CHEN F.C., ZHANG W.Y. Intraspecific and interspecific competition intensity of Parrotia subaequalis in different habitats from Wanfoshan Nature Reserve, Anhui Province. Chinese Journal of Ecology. 35 (7), 1744, 2016.

40. LI C., PEI S.X., ZHANG L.J., GUO J., XIN X.B. Applicability evaluation of competition indexes for Pinus tabuliformis plantations in Beijing. Journal of Zhejiang A\&F University. 36 (6), 1115, 2019.

41. WANG X.X., ZHANG Q.D., BI R.C., BAI Y.F. Intra-and interspecific competition of rare and endangered plant Ulmus lamellosa in Shanxi Province of China. Chinese Journal of Ecology. 32 (7), 1756, 2013.

42. LUO M., CHEN S.Z. Intraspecific and interspecific competition of Larix olgensis plantations in different age groups. Journal of Beijing Forestry University. 40 (9), 33, 2018.

43. WANG F., JU S.M. Research progress on Pinaceae mycorrhizae. Guizhou Agricultural Sciences. 38 (10), 92, 2010. 